\title{
Estuarine consumers utilize marine, estuarine and terrestrial organic matter and provide connectivity among these food webs
}

\author{
Ester Dias $^{1,2, *}$, Pedro Morais ${ }^{2,3}$, Anne M. Cotter ${ }^{4}$, Carlos Antunes ${ }^{2,5}$, \\ Joel C. Hoffman ${ }^{4}$ \\ ${ }^{1}$ ICBAS - Instituto de Ciências Biomédicas Abel Salazar, Universidade do Porto, Rua de Jorge Viterbo Ferreira 228, \\ 4050-313 Porto, Portugal \\ ${ }^{2}$ CIMAR/CIIMAR - Centro Interdisciplinar de Investigação Marinha e Ambiental, Universidade do Porto, \\ Rua dos Bragas 289, 4050-123 Porto, Portugal \\ ${ }^{3}$ CCMAR - Centre of Marine Sciences, Campus de Gambelas, Universidade do Algarve, 8005-139 Faro, Portugal \\ ${ }^{4}$ Mid-Continent Ecology Division, National Health and Environmental Effects Research Lab, \\ US Environmental Protection Agency, 6201 Congdon Blvd, Duluth, MN 55804, USA \\ ${ }^{5}$ Aquamuseu do Rio Minho, Parque do Castelinho s/n, 4920-290 Vila Nova de Cerveira, Portugal
}

\begin{abstract}
The flux of organic matter (OM) across ecosystem boundaries can influence estuarine food web dynamics and productivity. However, this process is seldom investigated taking into account all the adjacent ecosystems (e.g. ocean, river, land) and different hydrological settings (i.e. river discharge). Therefore, we aimed to quantify the contribution of autochthonous and allochthonous OM to the lower food web along the estuarine salinity gradient, under different river discharge conditions. The carbon $(\mathrm{C})$ and nitrogen $(\mathrm{N})$ stable isotope ratios of pelagic (zooplankton) and benthic (Corbicula fluminea) primary consumers indicated that they rely on a mixture of autochthonous and allochthonous OM, including terrestrial-derived OM. Unexpectedly, the highest contribution of terrestrial-derived OM to the estuarine food web was observed during a low river discharge period (up to $70 \%$ ), that succeeded a large winter flood, showing that extreme weather events may produce prolonged effects on estuarine food webs. The contribution of marine-derived OM was higher during low river discharge periods (up to $88 \%$ ) and was restricted to the seaward end of the estuary. Concomitantly, the contribution of phytoplankton to primary consumers was the highest observed (up to $91 \%$ ). Further, both pelagic and benthic consumers also relied on benthic C (i.e. sediment OM and microphytobenthos). This study demonstrates that primary consumers enhance connectivity between estuarine ecosystems by utilizing subsidies of terrestrial and marine origin, and also between estuarine habitats through reliance on pelagic and benthic OM.
\end{abstract}

KEY WORDS: Allochthonous organic matter $\cdot$ River discharge $\cdot$ Pelagic $\cdot$ Benthic $\cdot$ Stable isotopes Extreme weather events

Resale or republication not permitted without written consent of the publisher-

\section{INTRODUCTION}

Estuaries are highly productive ecosystems functioning within a mosaic of habitats. Connectivity between habitats is facilitated by physical exchanges of water and movements or migrations of animals (Vanni et al. 2004, Sheaves 2009, Hoffman et al.
2015). The cross-habitat movements of nutrients and organic matter (OM) can influence food web dynamics and productivity in the recipient estuarine habitat (Nixon \& Buckley 2002, Riley et al. 2004). Mechanisms for cross-habitat exchanges include landwater coupling, downstream transport of nutrients and $\mathrm{OM}$, and intrusion of nearshore nutrients and 
OM (Valiela \& Bartholomew 2015). Downstream transport of riverine and terrestrial nutrients can enhance estuarine primary (Riley et al. 2004) and secondary production (Valiela \& Bartholomew 2015). Moreover, terrestrial-derived particulate OM can support secondary production in estuaries (Antonio et al. 2010, Cole \& Solomon 2012, Dias et al. 2014). Organic matter can also enter the estuaries as a result of marine intrusion or by fish migrations (Naiman et al. 2002, Kohler et al. 2012).

The magnitude of nutrient and OM subsidies to estuarine food webs can vary greatly over time and space (Vanni et al. 2004). The hydrologic balance between freshwater runoff and intruding nearshore waters influences organic matter and nutrient exchange. During high river discharge periods, riverine and terrestrial OM inputs to the estuary can increase, augmenting terrestrial-derived OM utilization by aquatic consumers (Hoffman et al. 2008, Atwood et al. 2012). Contrarily, during low discharge periods, residence time is elongated, allowing estuarine phytoplankton biomass to accumulate (Hoffman \& Bronk 2006).

Further, diurnal (tidal) and lunar (spring-neap) cycles deliver subsidies to different estuarine areas along the freshwater-marine gradient (Riley et al. 2004), while episodic weather events can alter the magnitude and direction of material transferred between ecosystems (Goñi et al. 2009, Valiela \& Bartholomew 2015). Thus, because external subsidies (i.e. terrestrial- or marine-derived OM) may alter the carrying capacity of estuaries, understanding both the dependence of estuarine food webs upon adjacent ecosystems and the mechanisms influencing the relative strength of this dependence is crucial for management and conservation.

Characterizing estuarine food webs is challenging because estuaries receive OM inputs from many sources, including riparian vegetation, submerged and emergent aquatic vegetation (and associated epiphytic algae), phytoplankton and microphytobenthos (Cloern et al. 2002, Hoffman \& Bronk 2006). These sources can be classified as autochthonous (i.e. local photosynthetic production) or allochthonous (i.e. sources produced in adjacent regions, which can include riparian and upland vegetation). Stable isotopes are well-suited to characterizing food webs at the landscape level. Carbon (C) and nitrogen (N) stable isotopes $\left({ }^{13} \mathrm{C} /{ }^{12} \mathrm{C}\right.$ and $\left.{ }^{15} \mathrm{~N} /{ }^{14} \mathrm{~N}\right)$ can distinguish among different autotrophs, because they will differ with respect to $\mathrm{C}$ and $\mathrm{N}$ source and method of C fixation (Smith \& Epstein 1971, Fry \& Sherr 1984, Peterson \& Fry 1987, France 1995, Cloern et al. 2002, Hoff- man \& Bronk 2006), thus providing the basis for determining the habitats from which they originated.

Thus, this study aimed to characterize the contribution of different OM sources supporting the lower food web of a temperate estuary along the salinity gradient, under naturally varying river discharge. We hypothesized that the contribution of terrestrialderived $\mathrm{OM}$ to the estuarine food web would increase during periods of high river discharge, and would be greatest in the tidal freshwater, whereas marine-derived OM would be greatest in the polyhaline estuary and at the end of the low river discharge period. We also hypothesized that if phytoplankton is available, primary consumers would respond by preferentially deriving energy from this high-quality food source; however, if phytoplankton is quantity limited, primary consumers would rely on a detritusbased food web or use alternative feeding strategies.

To test our hypothesis, we identified and quantified the contribution of different OM sources supporting the production of the most abundant primary consumers - zooplankton and the Asian clam Corbicula fluminea (Müller, 1774) — in the Minho River estuary (NW Iberian Peninsula, Europe) using $\mathrm{C}$ and N stable isotope analysis. These consumers were chosen because they represent pelagic and benthic habitats respectively, and because they have limited longitudinal movement and thus should reflect the conditions of the habitat in which they were collected. The study was conducted over the entire salinity gradient during 2 consecutive summer low discharge periods, and a contrasting winter high discharge period.

\section{MATERIALS AND METHODS}

\section{Study area}

The study was conducted in the river Minho (Fig. 1), which extends to a length of $343 \mathrm{~km}$, flowing NNE-SSW into the Atlantic Ocean (Ferreira et al. 2003). The limit of tidal influence is about $40 \mathrm{~km}$ inland, and the estuary has an area of $23 \mathrm{~km}^{2}$. The estuary is mesotidal with tides ranging between $0.7 \mathrm{~m}$ and $3.7 \mathrm{~m}$ (Alves 1996). The mean depth of the estuary is about $4 \mathrm{~m}$ and the maximum depth is $23 \mathrm{~m}$ (Reis et al. 2009).

\section{Field sampling}

Field sampling was carried out during full moon spring tides and at 21 stations located every kilo- 


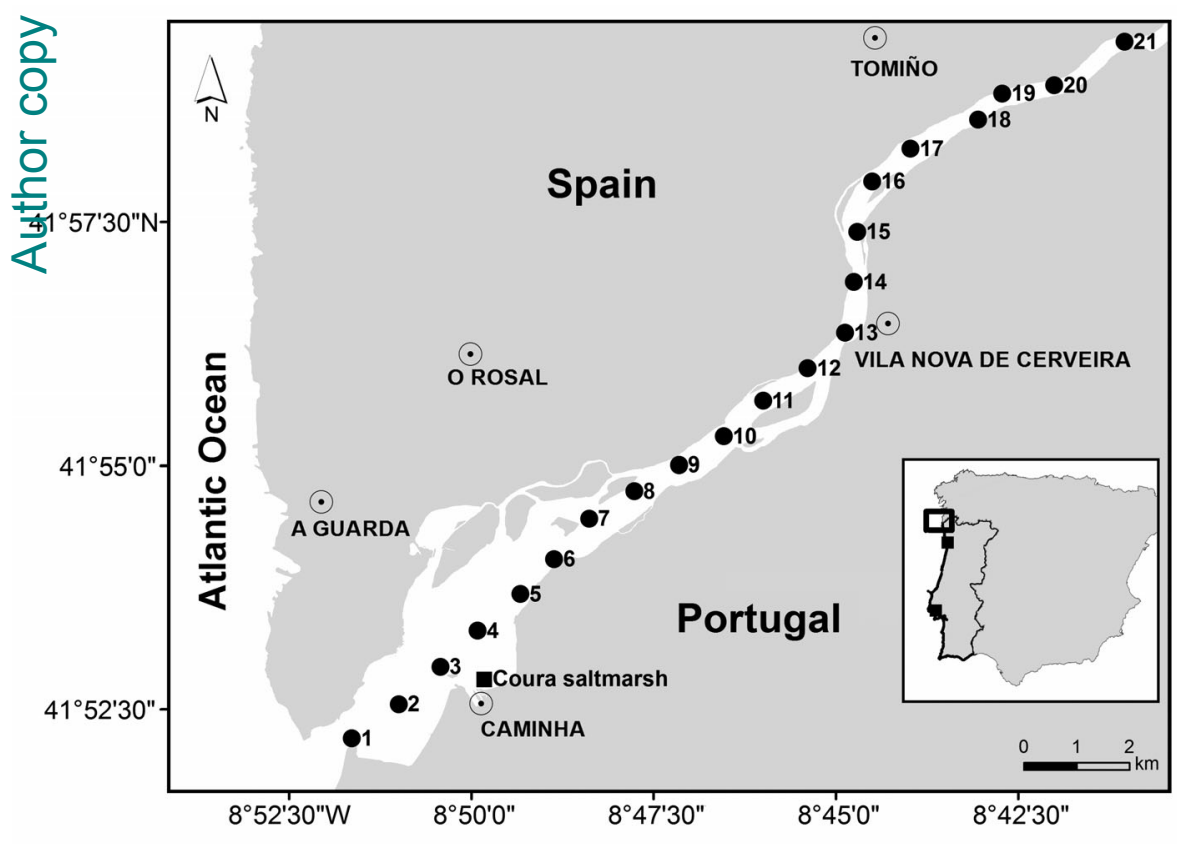

Fig. 1. Location of the sampling stations along the salinity gradient of the Minho River estuary

meter along the main river channel, to characterize the estuarine mixing zone (Fig. 1). Samples were collected in September 2010 and August 2011, to characterize low river discharge conditions (SNIRH 2012), and in March 2011 to characterize the end of high river discharge periods (SNIRH 2012; Fig. 2). During low river discharge, salt water intrusion is

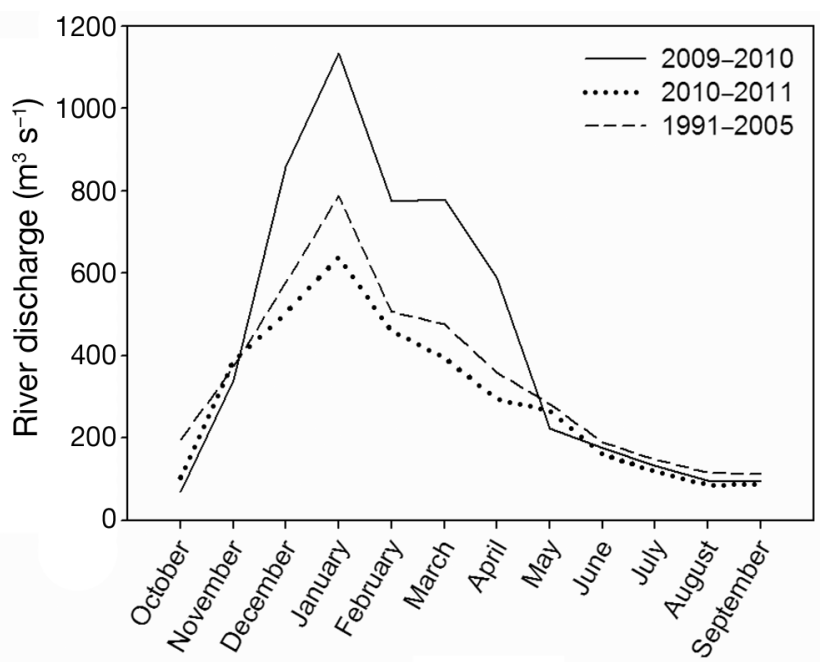

Fig. 2. Average monthly Minho River discharge measured between 1991 and 2005 (dashed line; gauge located at Foz do Mouro; SNIRH 2012) and October 2009 (solid line: 2009-2010) and September 2011 (dotted line: 2010-2011) (gauge located at Tui-Confederación Hidrográfica del Miño$\mathrm{Sil}_{;}$2012) maximized, favoring connectivity between the estuary and the marine environment, and residence time is prolonged, which allows phytoplankton biomass to accumulate. During high river discharge, estuarine residence time decreases, flushing phytoplankton seaward and suppressing its production (Sin et al. 1999, Branco \& Kremer 2005).

The OM sources sampled were selected based on the feeding modes of the primary consumers selected (zooplankton and Corbicula fluminea): phytoplankton (freshwater, estuarine and marine), macroalgae, microphytobenthos (MPB), sediment organic matter (SOM), particulate organic matter (POM), and vascular plants (terrestrial and aquatic; Cole et al. 2011, Dias et al. 2014).

At each station, surface $(50-100 \mathrm{~cm}$ below the surface) and bottom water samples ( $0.5 \mathrm{~m}$ off the bottom) were collected using a 21 Ruttner bottle. From these samples, we determined the chlorophyll a ( $\mathrm{chl}$ a) concentration $\left(\mu \mathrm{g} \mathrm{l}^{-1}\right)$, POM concentration $\left(\mathrm{mg} \mathrm{l}^{-1}\right)$ and isotopic composition (including particulate organic carbon [POC] $\delta^{13} \mathrm{C}$, particulate nitrogen $[\mathrm{PN}] \delta^{15} \mathrm{~N}$, and molar $\mathrm{C}: \mathrm{N}$ ), and isotopic composition of total dissolved inorganic carbon (DIC $; \delta^{13} \mathrm{C}_{\text {DIC }}$ ). Salinity was measured with a YSI model 6820 QS probe and reported using the Practical Salinity Scale.

The POM and chl a water samples were pre-filtered with a $150 \mu \mathrm{m}$ sieve and filtered onto pre-combusted $\left(500^{\circ} \mathrm{C}\right.$ for $\left.2 \mathrm{~h}\right)$ Whatman GF/F and Whatman $\mathrm{GF} / \mathrm{C}$ filters, respectively, and kept frozen $\left(-20^{\circ} \mathrm{C}\right)$ until analysis.

The DIC samples (taken from replicate water samples) were injected $(6 \mathrm{ml})$ into a $10 \mathrm{ml}$ Exetainer ${ }^{\circledR}$ (Labco Limited), containing $0.5 \mathrm{ml}$ of phosphoric acid $85 \%(\mathrm{v} / \mathrm{v})$, with a sterile syringe filter coupled with a $0.2 \mu \mathrm{m}$ cellulose acetate membrane acrodisc. Samples were kept cool during field sampling and then stored at $4^{\circ} \mathrm{C}$ until $\delta^{13} \mathrm{C}_{\text {DIC }}$ analysis.

The MPB samples were collected at 4 stations situated across the salinity gradient (Stns 1, 9, 16, 21). At each station, an artificial substrate was fixed in the sediment and left in the estuary for $2 \mathrm{wk}$. At the end of this period, colonizing algae were scraped from the substrate into a clean vial, stored on ice, and returned to the laboratory where the same procedure used for POM samples was applied. Macroalgae 
were collected at Stns 1 and 9 (higher salinity influence), and vascular plants in Stns 9, 16 and 21 (areas with abundant vegetation). The SOM samples were collected using a van Veen grab and were kept frozen $\left(-20^{\circ} \mathrm{C}\right)$ until analysis.

Zooplankton primary consumers were collected, at each station, with a plankton net (200 $\mu \mathrm{m}$ mesh size) towed near the surface at a constant speed for $3 \mathrm{~min}$. Samples were immediately preserved in $70 \%$ ethanol. The C. fluminea specimens were collected using a van Veen grab. Ten clams per station and sampling period were randomly selected for analysis (420 specimens total) and kept frozen $\left(-20^{\circ} \mathrm{C}\right)$ until analysis.

\section{Laboratory analyses}

Filters processed for $\mathrm{chl}$ a analysis were extracted in $90 \%$ acetone and analyzed on a Spectronic 20 Genesys spectrophotometer. Chl a concentration was calculated following Lorenzen (1967).

Filters for POM and MPB analyses were fumed with concentrated $\mathrm{HCl}$ to remove inorganic carbonates, and dried at $60^{\circ} \mathrm{C}$ for $24 \mathrm{~h}$ (Lorrain et al. 2003). Sediment samples were rinsed with $10 \% \mathrm{HCl}$ (also to remove carbonates), and dried at $60^{\circ} \mathrm{C}$ for $48 \mathrm{~h}$. Macroalgae and vascular plants were cleaned with deionized water, dried $\left(60^{\circ} \mathrm{C}\right)$, and ground to a fine powder with a mixer mill for stable isotope analysis.

Zooplankton individuals were sorted, identified, grouped by the lowest taxonomic level feasible, and dried $\left(60^{\circ} \mathrm{C}\right)$. For $C$. fluminea, the shell length of each specimen was measured $( \pm 0.01 \mathrm{~mm})$. Then, the foot was excised, dried $\left(60^{\circ} \mathrm{C}\right)$, and ground to a fine powder with a mortar and pestle for stable isotope analysis.

Stable isotope ratios were measured using a Costec 4010 EA and Thermo Delta Plus XP isotope ratio mass spectrometer (IRMS) (United States Environmental Protection Agency, Mid-Continent Ecology Divison, Duluth, MN) and a Thermo Scientific Delta V Advantage IRMS via Conflo IV interface (Marinnova, University of Porto). Stable isotope ratios are reported in $\delta$ notation, $\delta \mathrm{X}: \delta \mathrm{X}=\left(R_{\text {sample }} / R_{\text {standard }}-1\right) \times$ $10^{3}$, where $\mathrm{X}$ is the $\mathrm{C}$ or $\mathrm{N}$ stable isotope, $R$ is the ratio of heavy:light stable isotopes, and Pee Dee Belemnite and air are standards for $\delta^{13} \mathrm{C}$ and $\delta^{15} \mathrm{~N}$, respectively. The analytical error, the mean standard deviation of replicate reference material, was $\pm 0.1 \%$ for $\delta^{13} \mathrm{C}$ and $\delta^{15} \mathrm{~N}$. DIC $\delta^{13} \mathrm{C}$ was measured using a GasBench II system interfaced to a Delta V Plus IRMS (University of California Davis Stable Isotope Facility). The analytical error was $\pm 0.2 \% \delta^{13} \mathrm{C}$.

\section{Data analysis}

The relationship between environmental variables (salinity, river discharge, chl a) and the $\delta^{13} \mathrm{C}$ and $\delta^{15} \mathrm{~N}$ values of the primary consumers was assessed through a distance-based linear modeling (DistLM) (Anderson et al. 2008). The selection criterion adopted was the Akaike Information Criterion (AIC), and a stepwise selection procedure was used.

Multivariate analyses were performed to reveal natural groupings in the data according to sampling period and portion of the estuary. A cluster analysis was performed, using Euclidean similarity distance, on $\delta^{13} \mathrm{C}$ and $\delta^{15} \mathrm{~N}$ values of primary consumers data. A similarity profile routine (SIMPROF) was used to test for the presence of sample groups (Clarke et al. 2008). DistLM and cluster analyses were performed using PRIMER v.6.1.11 ${ }^{\circledR}$ (Clarke \& Gorley 2006) with PERMANOVA+1.0.1 (Anderson et al. 2008).

To quantify OM source contributions to the most frequently sampled zooplankton groups (calanoid copepods) and C. fluminea, we used the stable isotope mixing model in $\mathrm{R}$ that uses Bayesian inference to solve the indeterminate equations (i.e. more than $n+1$ sources relative to $n$ stable isotopes) and produce a probability distribution that represents the likelihood a given source contributes to the consumer (SIAR; Parnell et al. 2010). For modelling purposes, the estuary was divided into 3 portions based on salinity as a result of the DistLM routine: tidal freshwater (TFW), brackish and marine portions.

For the mixing model, the average $( \pm \mathrm{SD}) \delta^{13} \mathrm{C}$ and $\delta^{15} \mathrm{~N}$ values for the various OM sources were estimated. At each station, the phytoplankton $\delta^{13} \mathrm{C}$ $\left(\delta^{13} \mathrm{C}_{\text {phyto }}\right)$ value was estimated from the DIC $\delta^{13} \mathrm{C}$ $\left(\delta^{13} \mathrm{C}_{\text {DIC }}\right)$ value, assuming an uptake fractionation of $-21 \%$ (i.e. $\delta^{13} C_{\text {phyto }}=\delta^{13} C_{\text {DIC }}-21 \%$; Peterson \& Fry 1987). However, isotopic fractionation can vary with $\mathrm{CO}_{2}$ and nutrient concentration, and phytoplankton growth rates (Mook \& Tan 1991, de Kluijver et al. 2014). To corroborate the $\delta^{13} \mathrm{C}_{\mathrm{DIC}}$-based estimates, we estimated $\delta^{13} \mathrm{C}_{\text {phyto }}$ values using an independent method that yields similar $\delta^{13} \mathrm{C}$ values to isolated algae samples (see Eq. 2 in Marty \& Planas 2008). The method is a 2-source, single stable isotope mixing model that estimates $\delta^{13} \mathrm{C}_{\text {phyto }}$ by correcting particulate organic carbon $\delta^{13} \mathrm{C}\left(\delta^{13} \mathrm{C}_{\mathrm{POC}}\right)$ for the relative algal biomass contribution (percent algae), which is derived from the $\mathrm{chl} a$ concentration (C:chl $a=80$; Marty \& Planas 2008). The proportion of algal carbon in the POC pool was calculated according to Canuel et al. (1995). The $\delta^{13} \mathrm{C}$ values used in the model were the average $\delta^{13} \mathrm{C}_{\mathrm{POC}}$ values measured in each region, 
and either the $\delta^{13} \mathrm{C}$ of terrestrial plants for the TFW $\left(\delta^{13} \mathrm{C}=-27 \%\right.$; this study) or else the $\delta^{13} \mathrm{C}$ of marine phytoplankton $\left(\delta^{13} \mathrm{C}=-21 \%\right.$; McMahon et al. 2013) for the polyhaline estuary.

For each portion of the estuary, the average $\delta^{13} \mathrm{C}_{\text {phyto }}$ value used in the SIAR mixing model was the mean of station-specific average surface and bottom $\delta^{13} \mathrm{C}_{\text {phyto }}$ values (based on station replicates) for those stations within each portion. The $\delta^{15} \mathrm{~N}_{\text {phyto }}$ values for the SIAR mixing model were obtained from POM sampled during August 2011 at all stations where the POM samples were comprised of nearly $100 \%$. For the model, the value used in the TFW and brackish portions of the estuary was the mean station-specific average $\delta^{15} \mathrm{~N}_{\text {phyto }}$ values for those stations within each portion. For the marine stations, we used the values reported by Bode et al. (2007) for the Iberian Peninsula Coast $\left(\delta^{15} \mathrm{~N}_{\text {phyto }}=6 \pm 1.5 \%\right.$ ) .

In the brackish portion of the estuary in August 2011, calanoid copepods Acartia spp. had a bi-modal isotopic distribution, indicating the use of distinct OM sources within the same portion of the estuary. Thus, calanoid copepods were grouped by isotopic composition (AI and AII) and only calanoid copepod AII were included in the model because there were insufficient samples from AI. Also, consumers presenting $\delta^{13} \mathrm{C}$ and $\delta^{15} \mathrm{~N}$ falling outside the range of the OM sources sampled were not included in the model.

Average MPB, POM, and SOM $\delta^{13} \mathrm{C}$ and $\delta^{15} \mathrm{~N}$ values were calculated from all the values from those stations within each portion of the estuary.

Zooplankton and C. fluminea $\delta^{13} \mathrm{C}$ values were corrected for lipid content because lipids are depleted in ${ }^{13} \mathrm{C}$ compared to protein and carbohydrates (DeNiro \& Epstein 1977), according to the mass balance correction models of Smyntek et al. (2007, their Eq. 5) and Logan et al. (2008, their Eq. 2), respectively. Zoo-

Table 1. Characterization of the particulate organic matter (POM) pool, and dissolved inorganic carbon $\delta^{13} \mathrm{C}\left(\delta^{13} \mathrm{C}_{\text {DIC }}\right)$ in the Minho River estuary, along the salinity mixing gradient in September 2010, March and August 2011. Data are means (SD). POC: particulate organic carbon; $\mathrm{F}_{\text {phyto }}$ : proportion of phytoplankton; TFW: tidal freshwater

\begin{tabular}{|lccccc|}
\hline Month & Location & C:N $\mathrm{N}_{\text {POM }}$ & POC $(\mu \mathrm{M})$ & $\mathrm{F}_{\text {phyto }}(\%$ POC $)$ & $\delta^{13} \mathrm{C}_{\text {DIC }}(\%)$ \\
\hline September & TFW & $10.2(0.9)$ & $29.0(11.9)$ & $17.2(18.8)$ & $-17.8(0.5)$ \\
2010 & Brackish & $8.3(1.1)$ & $25.8(13.1)$ & $18.7(14.0)$ & $-8.2(4.7)$ \\
March & TFW & $8.4(1.6)$ & $17.9(6.3)$ & $30.0(21.4)$ & $-10.8(0.5)$ \\
2011 & Brackish & $9.2(1.9)$ & $11.9(4.9)$ & $36.8(26.2)$ & $-1.5(2.5)$ \\
August & TFW & $7.0(0.5)$ & $27.0(4.8)$ & $74.4(19.0)$ & $-10.0(0.3)$ \\
2011 & Brackish & $7.0(1.1)$ & $27.5(7.8)$ & $56.6(25.6)$ & $-4.1(3.2)$ \\
& Marine & $8.7(2.6)$ & $16.3(4.6)$ & $7.7(5.1)$ & $0.4(0.3)$ \\
\hline
\end{tabular}

plankton were also corrected for ethanol preservation $\left(+0.4 \% \delta^{13} \mathrm{C}_{1}+0.6 \%\right.$ o $\delta^{15} \mathrm{~N}_{i}$ Feuchtmayr \& Grey 2003). For the SIAR mixing model, the $\delta^{13} \mathrm{C}$ and $\delta^{15} \mathrm{~N}$ values were adjusted for 1 trophic level using the trophic fractionation estimates from Post (2002) $\left(+0.4 \pm 1.3 \%{ }^{13} \mathrm{C}_{1}+3.4 \pm 1.0 \%{ }^{15} \mathrm{~N}\right)$.

\section{RESULTS}

\section{Environmental data}

The average river discharge observed in September 2010 and August 2011 were close to the typical low river discharge values in the Minho River estuary, and March 2011 average river discharge values were typical for the end of the wet season (Fig. 2).

In September 2010, the saltwater intrusion was detected up to $12 \mathrm{~km}$ from the river mouth (Stns 1-13 were brackish, Stns 14-21 were within the tidal freshwater (TFW) area (Fig. 3A). In March 2011, Stns 1-6 were brackish and 7-21 were freshwater (Fig. 3B). In August 2011, the saltwater intrusion was detected up to $16 \mathrm{~km}$ from the mouth (Stns 1-6 were marine, Stns 7-16 were brackish, and Stns 17-21 were freshwater) (Fig. 3C).

The quality and quantity of POM varied along the estuary and between sampling periods (Table 1). In September 2010, C: $\mathrm{N}_{\mathrm{POM}}>10$ indicates a contribution of terrestrial-derived OM to the POM pool in the TFW (Hedges et al. 1986, 1997). In the brackish portion of the estuary, $C: \mathrm{N}_{\mathrm{POM}}$ ratio varied between the $\mathrm{C}: \mathrm{N}$ ratios of terrestrial-derived $\mathrm{OM}(>10)$ and marine phytoplankton $(\sim 7)$ (Hedges et al. 1986, 1997), indicating that brackish POM was a mixture of riverine and marine POM (Table 1). In March 2011 C: $\mathrm{N}_{\mathrm{POM}}$ varied between 6 and 12, indicating that the POM pool was a mixture of phytoplankton and terrestrial-derived OM (Table 1). In August 2011, C: $\mathrm{N}_{\mathrm{POM}}$ was $\sim 7$, the estimates of the phytoplankton proportion in the POM pool $(>50 \%)$ and high chl a concentrations indicate that phytoplankton was a major contributor to the POM pool (Table 1, Fig. 3D-F). The POC concentrations in September 2010 and August 2011 were almost double those measured in March 2011, and the concentration values were similar along the estuarine salinity gradient (Table 1). 

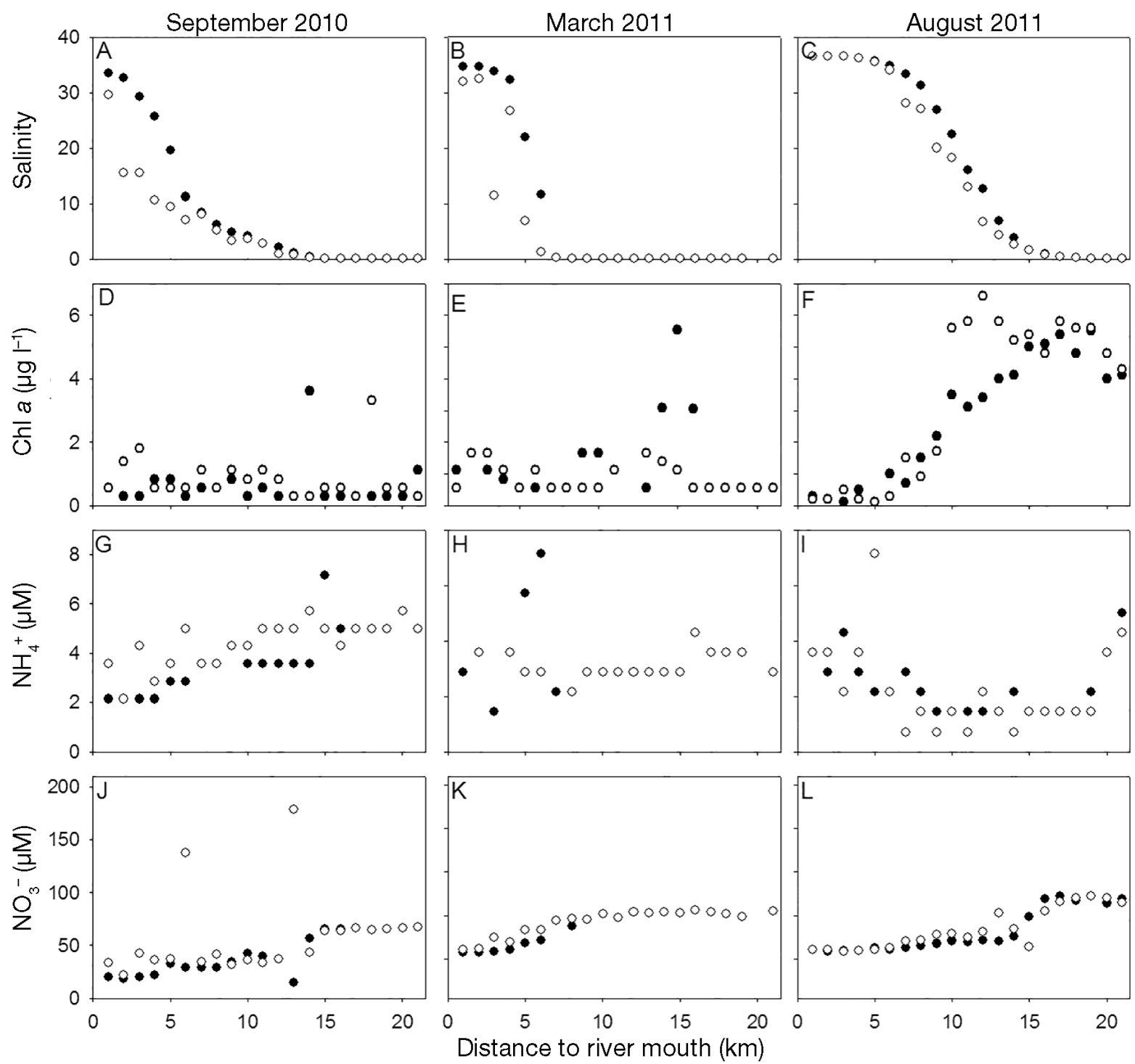

Fig. 3. Bottom (•) and surface (O) (A-C) salinity, (D-F) chlorophyll a (chl a) concentration $\left(\mu \mathrm{l}^{-1}\right),(\mathrm{G}-\mathrm{I})$ ammonium $\left(\mathrm{NH}{ }_{4}^{+}\right)$and $(\mathrm{J}-\mathrm{L})$ nitrate $\left(\mathrm{NO}_{3}{ }^{-}\right)$concentrations $(\mu \mathrm{M})$ measured in the Minho River estuary in September 2010 (low discharge), March 2011 (high discharge), and August 2011 (low discharge)

\section{Stable isotope composition}

Based on the DistLM analysis, salinity and chl a concentration accounted for the most variability in zooplankton and C. fluminea $\delta^{13} \mathrm{C}$ and $\delta^{15} \mathrm{~N}$ values ( $50 \%$ of the total variance; Table 2 ). Zooplankton and C. fluminea $\delta^{13} \mathrm{C}$ and $\delta^{15} \mathrm{~N}$ values did not demonstrate a significant association with river discharge (Table 2).

Cluster analysis results corroborate that salinity was the primary factor structuring consumers' $\delta^{13} \mathrm{C}$ and $\delta^{15} \mathrm{~N}$ values (Fig. 4). The first branch separates ${ }^{13} \mathrm{C}$-enriched and ${ }^{15} \mathrm{~N}$-depleted consumers (Group
Table 2. DistLM model based on the $\delta^{13} \mathrm{C}$ and $\delta^{15} \mathrm{~N}$ values of zooplankton and Corbicula fluminea and fitted abiotic data

\begin{tabular}{|lrrrcc|}
\hline Variable & AIC & $\begin{array}{c}\text { SS } \\
\text { (trace) }\end{array}$ & $\begin{array}{c}\text { Pseudo- } \\
F\end{array}$ & $p$ & $\begin{array}{c}\text { Proportion } \\
(\%)\end{array}$ \\
\hline Marginal tests & & & & \\
Salinity & 58.26 & 41.76 & $<0.05$ & 31.0 \\
River discharge & 5.17 & 2.63 & 0.075 & 2.75 \\
Chl a & 39.41 & 24.66 & $<0.05$ & 21.0 \\
Sequential tests & & & & \\
Salinity & 33.61 & 58.26 & 41.76 & $<0.05$ & 31.0 \\
Chl a & 5.61 & 35.12 & 34.15 & $<0.05$ & 19.0 \\
\hline
\end{tabular}




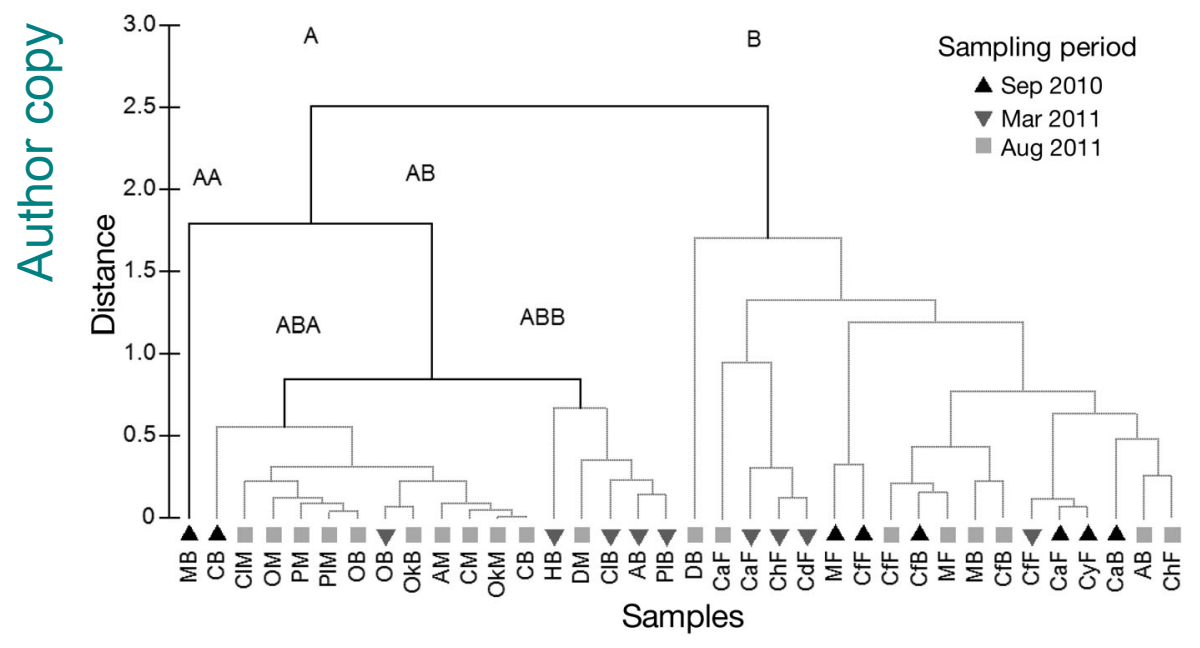

Fig. 4. Clustering analyses of primary consumers' $\delta^{13} \mathrm{C}$ and $\delta^{15} \mathrm{~N}$ values collected in September $2010(\mathbf{\Delta})$, March $2011(\boldsymbol{\nabla})$ and August $2011(\square)$ in the marine (M), brackish (B) and tidal freshwater (F) portions of the Minho River estuary. Primary consumers include Calanus sp. (Cl), Acartia sp. (A), Centropages sp. (C), Calanoida (Ca), chironomidae larvae (Ch); Cyclopoida (Cy), Harpaticoida $(\mathrm{H})$, Cladocera $(\mathrm{Cd})$, Ostracoda (O), Caridea (M), Podon sp. (P), Decapoda (D), Polychaeta larvae (Pl), Oikopleura sp. (Ok), and Corbicula fluminea (Cf). The first letter(s) represents the species code and the last letter represents the portion of the estuary where they were collected ( $M, B$ or $F)$. Grey lines indicate groups of samples not separated (at $\alpha=0.05$ ) by SIMPROF

A) from those that were ${ }^{13} \mathrm{C}$-depleted and ${ }^{15} \mathrm{~N}$ enriched (Group B) (Figs. 4 \& 5). Group A was essentially comprised of marine and brackish zooplankton collected in August 2011 and March 2011
(Fig. 4). Group B included TFW organisms (benthic and pelagic) and some ${ }^{15} \mathrm{~N}$-enriched consumers (e.g. decapoda larvae, C. fluminea) collected in the brackish stations (Figs. 4 \& 5).
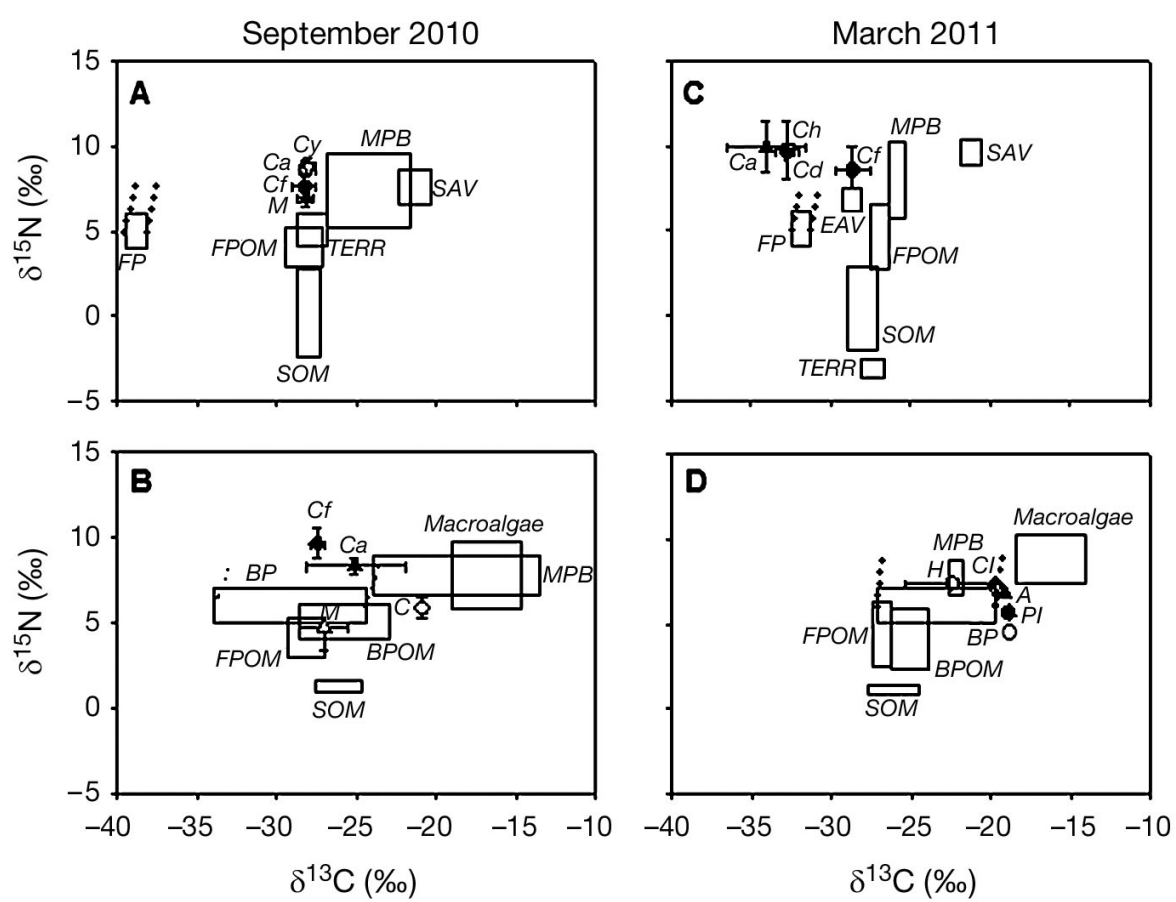

Fig. 5. Average stable isotope ratios $( \pm \mathrm{SD})$ of primary consumers collected in the $(A, C, E)$ tidal freshwater, $(B, D, F)$ brackish, and $(G)$ marine portions of the Minho River estuary in September 2010 (A-B; data partially published in Dias et al. 2014), March 2011 (C-D), and August 2011 (E-G). Organic matter (OM) sources include freshwater (FP), brackish (BP), and marine (MP) phytoplankton, freshwater (FPOM), brackish (BPOM), and marine (MPOM) particulate OM, microphytobenthos (MPB), submerged (SAV) and emergent (EAV) aquatic vegetation, terrestrial plants (TERR), macroalgae and sediment OM (SOM). Primary consumers species codes as in Fig. 4. Boxes represent the ranges for the sources collected during this study. Dotted lines indicate the expected stable isotope ratio of consumers utilizing phytoplankton, assuming typical trophic fractionation $\left(+0.4 \%{ }^{13} \mathrm{C}\right.$ and $+3.4 \%$ o $\delta^{15} \mathrm{~N}$ per trophic level)
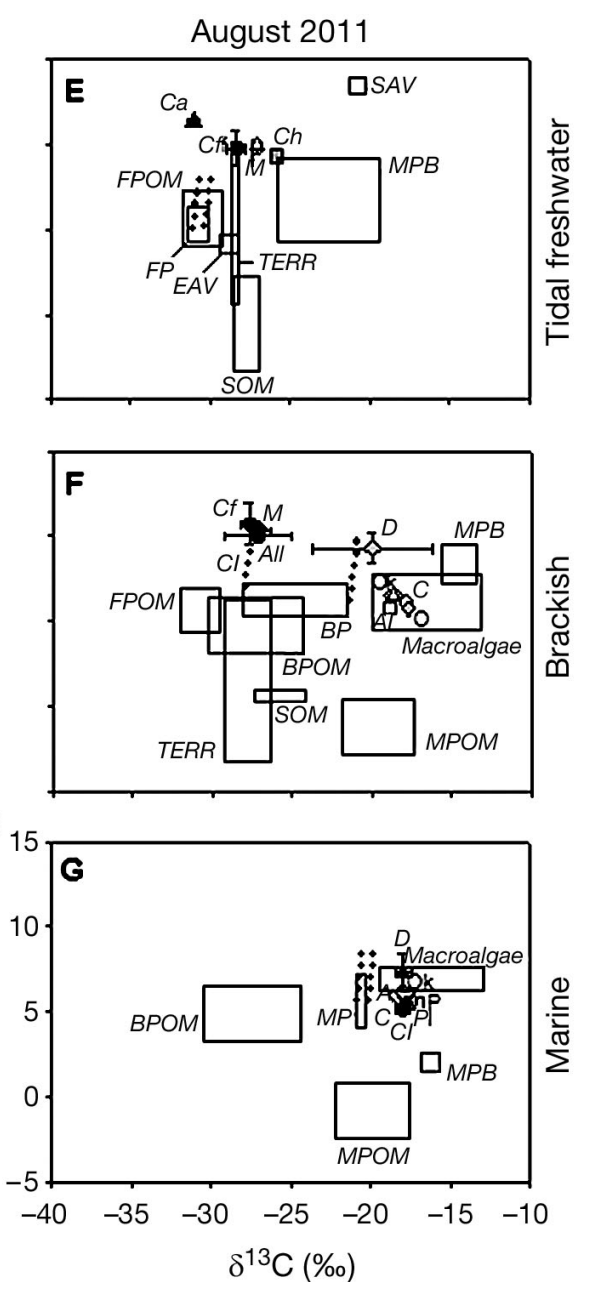
Within Group A, Group AA included Caridea shrimp larvae collected in September 2010 and Group $\mathrm{AB}$ included pelagic grazers and omnivorous zooplankton. Caridea larvae from Group AA had the lowest $\delta^{15} \mathrm{~N}$ values. Within Group $\mathrm{AB}$, Groups $\mathrm{ABA}$ and ABB essentially separate the zooplankton collected in August 2011 from those collected in March 2011, which were ${ }^{13} \mathrm{C}$-depleted and ${ }^{15} \mathrm{~N}$-enriched (Fig. 4).

\section{Food web characterization}

In the TFW portion of the estuary, OM sources were isotopically well-differentiated. However, the stable isotope ratios of phytoplankton and POM, and MPB and macroalgae were similar to each other in the brackish portion of the estuary (Fig. 5).

The $\delta^{13} C_{\text {phyto }}$ estimates based on $\delta^{13} C_{\text {DIC }}$ values were overall similar to those based on $\delta^{13} \mathrm{C}_{\mathrm{POC}}$ values, corroborating our estimates. For the TFW portion, the differences between the $\delta^{13} \mathrm{C}_{\text {phyto }}$ values from the 2 different methods varied between $0 \%$ (bottom water samples in August 2011) and $7 \%$ (surface water samples in August 2011). In August 2011, we sampled some stations where the estimated contribution of phytoplankton to the POM pool was close to $100 \%$. At those stations, the difference between $\delta^{13} \mathrm{C}_{\text {phyto }}$ values from the 2 methods was only $0.3 \%$. For the polyhaline portion, the difference between $\delta^{13} \mathrm{C}_{\text {phyto }}$ values estimated by the 2 methods was less than $4 \%$ for bottom water samples, but ranged from $7 \%$ to $11 \%$ for the surface water samples, with the $\delta^{13} \mathrm{C}_{\mathrm{POC}^{-}}$ based approach providing the lowest (most negative) $\delta^{13} \mathrm{C}_{\text {phyto }}$ estimates. Most likely, more than 2 sources were contributing to POM in polyhaline surface stations, violating the fundamental assumption of the $\delta^{13} \mathrm{C}_{\mathrm{POC}}$-based approach. Nonetheless, the estimates from $\delta^{13} \mathrm{C}_{\text {DIC }}$ provided similar values $(-25.5 \%$ to $-20.6 \%$ ) to those expected for areas under the marine influence (marine phytoplankton/seston: $-23 \%$ to $-18 \%$; Fry \& Sherr 1984, Chanton \& Lewis 2002, McMahon et al. 2013).

Zooplankton and C. fluminea stable isotope values, after adjusting for trophic fractionation, were generally intermediate between the OM sources measured, indicating reliance on multiple OM sources. In TFW, both zooplankton and C. fluminea stable isotope ratios indicated reliance on freshwater phytoplankton and plant detritus (Fig. 5A,C,E). In September 2010, the stable isotope ratios of consumers fell within the range of terrestrial-derived POM stable isotope ratios, suggesting a relevant contribution of this source to the estuarine food web (Fig. 5A). In
August 2011, the graphical analysis indicates increasing proportional contribution of phytoplankton to the consumers' biomass (Fig. 5E). In the brackish portion of the estuary, the isotopic composition of $C$. fluminea was consistent with consumption of a mixture of ${ }^{13} \mathrm{C}$-depleted sources such as freshwater POM (FPOM) or brackish POM (BPOM) and phytoplankton, and ${ }^{15} \mathrm{~N}$-enriched sources, such as MPB or macroalgae detritus (Fig. 5B,D,F). The stable isotope ratios among zooplankton taxa varied by month. In September 2010, the isotopic composition of Caridea larvae indicated reliance on ${ }^{13} \mathrm{C}$-depleted sources, such as terrestrial-derived FPOM or SOM (or both), whereas the isotopic composition of Calanus spp. indicated reliance on ${ }^{13} \mathrm{C}$-enriched sources such as MPB or macroalgae (Fig. 5B). In March 2011, the high $\delta^{13} \mathrm{C}$ values of zooplankton indicated the consumption of ${ }^{13} \mathrm{C}$-enriched sources such as macroalgae detritus (Fig. 5D). In August 2011, Caridea larvae and calanoid copepods (AII), had the lowest $\delta^{13} \mathrm{C}$ values (Group 1); Oikopleura spp., Calanus spp., Ostracoda and calanoid copepods (AI) had the highest $\delta^{13} \mathrm{C}$ values (Group 2); and Anomura crab larvae had intermediate $\delta^{13} \mathrm{C}$ and $\delta^{15} \mathrm{~N}$ values (Group 3; Fig. 5F). Group 1 was likely relying on a mixture of terrestrial plant detritus, POM, microalgae and MPB, whereas Group 2 was likely relying on some mixture of marine POM (MPOM), BPOM and macroalgae detritus, and Group 3 on a mixture of ${ }^{13} \mathrm{C}$-enriched zooplankton, macroalgae and brackish phytoplankton. In the marine portion of the estuary, zooplankton stable isotope ratios were consistent with consumption of MPOM and MPB (Fig. 5G).

The contribution from the various OM sources to the primary consumers varied by sampling period and portion of the estuary (Fig. 6). Among sampling periods, the most relevant difference was the substantial phytoplankton contribution to the primary consumers in August 2011 ( $\mathrm{F}_{\text {phyto }}>50 \%$; Fig. 6). The opposite occurred in September 2010, when calanoid copepods and C. fluminea were generally supported by terrestrial-derived OM (calanoid copepods, 20$40 \%$; C. fluminea, $40 \%$; Fig. 6). As hypothesized, terrestrial-derived $\mathrm{OM}$ contribution was greatest in TFW stations (plant detritus and FPOM), while the contribution of macroalgae and MPOM to calanoid copepods increased with the proximity to the river mouth (Fig. 6). The external subsidies to the estuarine food web also included the downstream transport of OM from TFW, which subsidized the brackish food web, namely by terrestrial-derived FPOM in September 2010 (20-40\%), and phytoplankton enriched FPOM in August 2011 (45-75\%) (Fig. 6). 

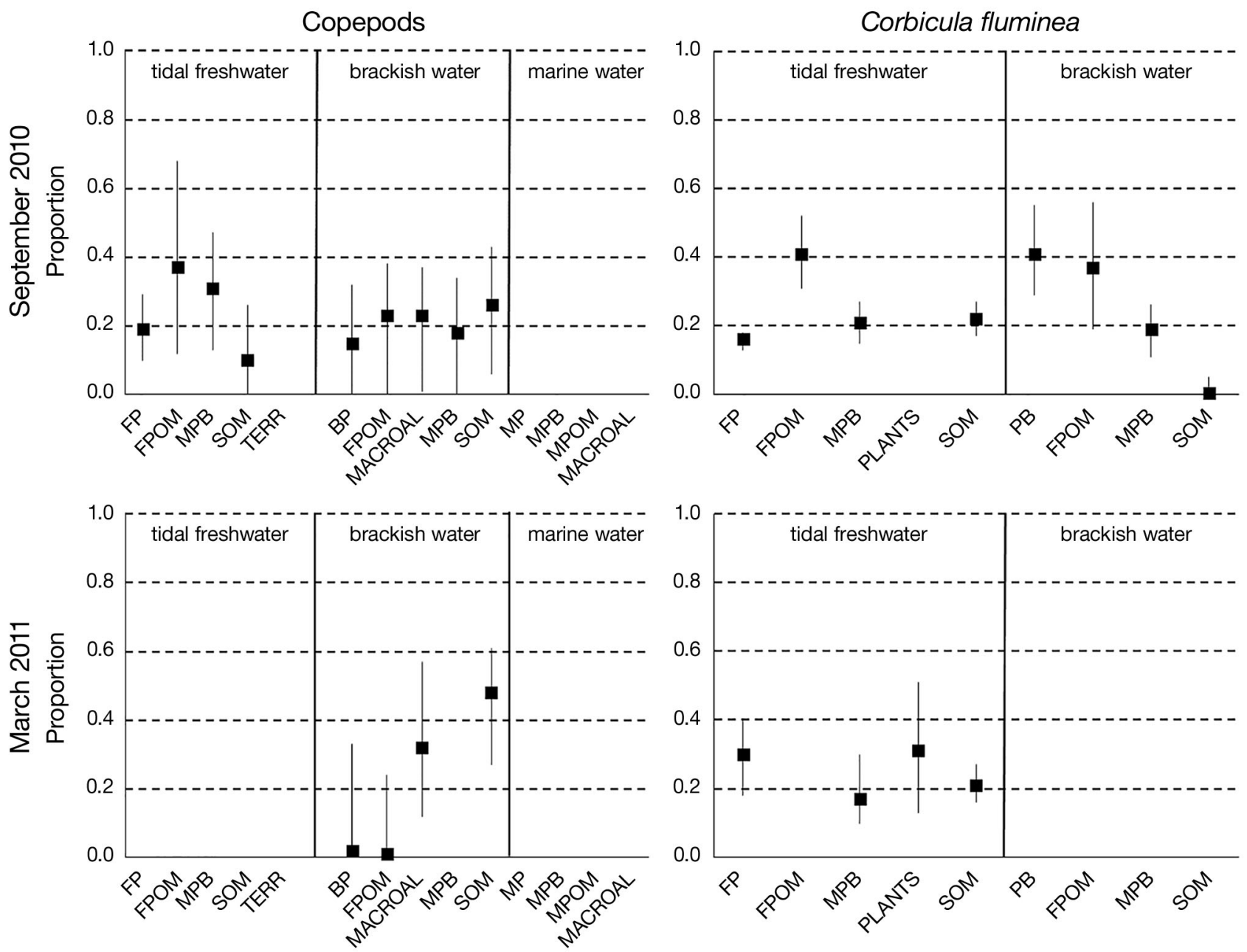

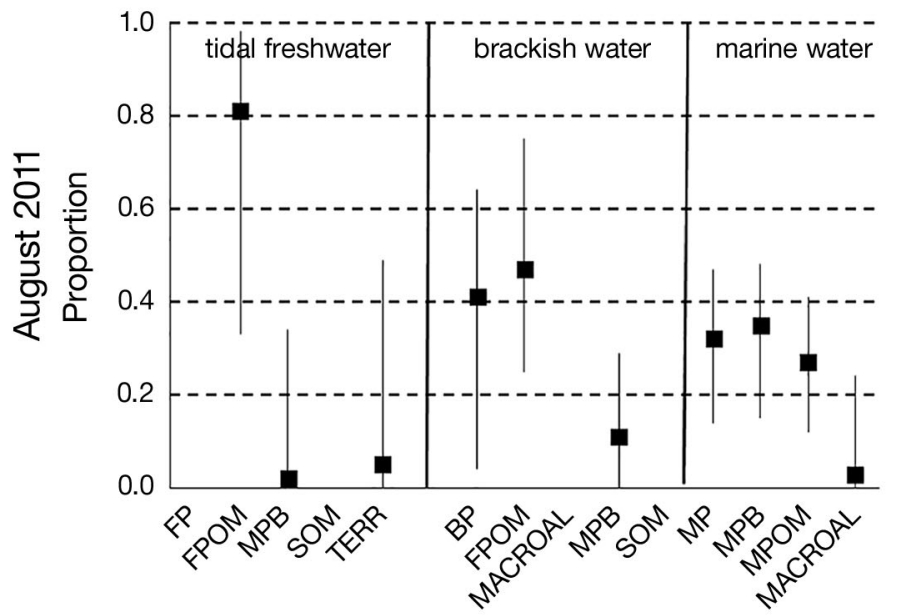

Sources
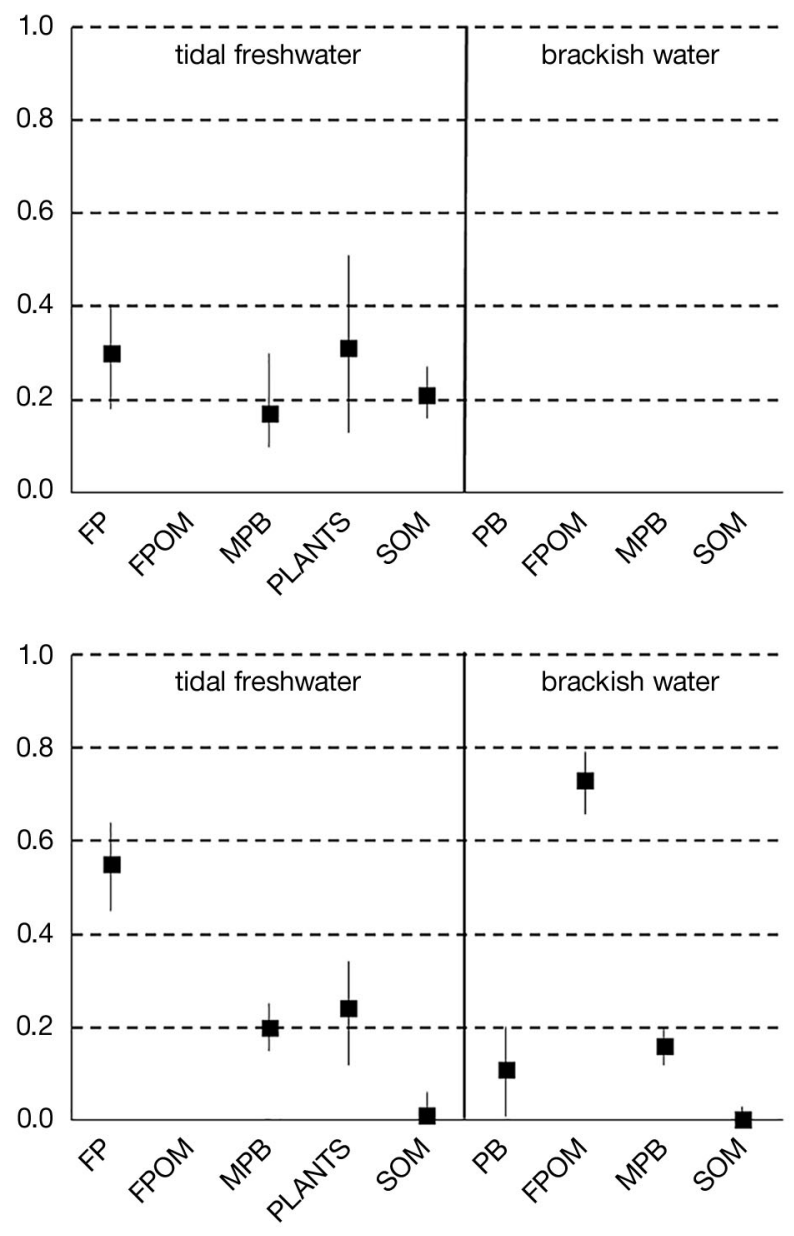

Sources

Fig. 6. Proportion of each food source to calanoid copepod (left panels) and Corbicula fluminea (right panels) biomass collected in the tidal freshwater, brackish and marine portions of the estuary in September 2010, March 2011 and August 2011. Food sources included in the model were freshwater, brackish and marine phytoplankton (FP, BP and MP), freshwater and marine particulate organic matter (FPOM and MPOM), microphytobenthos (MPB), sediment organic matter (SOM), terrestrial plants (TERR), macroalgae (MACROAL) and terrestrial or emergent aquatic vegetation (PLANTS). Closed squares indicate the most likely value (mode) and lines indicate the 95\% Bayesian credibility intervals. Where no value is shown, sources were not included as end-members in the model 


\section{DISCUSSION}

The quality of OM available for primary consumers in the Minho river estuary varied markedly between sampling periods. Stable isotope analysis, in concert with POM C:N ratios and estimates of phytoplankton fraction in the $\mathrm{POC}$, indicate that terrestrial-derived OM was the principal component of the POM pool in September 2010, whereas phytoplankton dominated the POM pool in August 2011. A corresponding shift was observed in the isotopic composition of pelagic and benthic consumers. Most pelagic (calanoid copepods) and benthic (C. fluminea) biomass was terrestrial-derived OM in September 2010, and phytoplankton-derived in August 2011. Notably, these months correspond to periods of low river discharge. Also, the stable isotope ratios of the primary consumers indicated that they can consume (or indirectly utilize) terrestrial-derived $\mathrm{OM}$ as well as both pelagic and benthic OM sources, and thereby directly link both terrestrial and estuarine ecosystems as well as pelagic and benthic habitats. Here, we discuss the role of river discharge, food web model assumptions, and evidence for cross-habitat and cross-ecosystem connectivity.

\section{Role of river discharge}

Overall, the contribution of external inputs to the estuarine food web was higher during the low river discharge periods. Allochthonous OM (i.e. terrestrialderived $\mathrm{OM}$ ) contribution to the primary consumers was higher during September 2010, decreasing seaward. The contribution of marine OM (i.e. marine phytoplankton, macroalgae, MPOM) increased during August 2011 but was limited to the mouth of the estuary.

We hypothesized that phytoplankton availability would increase during low river discharge, due to increased residence times. Although September 2010 and August 2011 had similar low discharge values, the quality of OM available was different. In September 2010, phytoplankton standing stock was low: phytoplankton proportion in the POM pool was $<20 \%$ and chl a concentration values were $<1 \mu \mathrm{g} \mathrm{l}^{-1}$. During the winter 2009-2010, a major flood occurred in the Minho River, and river discharge almost doubled historical values for this ecosystem (Fig. 2). This flood likely increased the amount of terrestrial-derived OM delivered to the estuary (Kendall et al. 2001, Hoffman et al. 2008). Although we did not measure allochthonous $\mathrm{C}$ loads to the estuary during the flood of 20092010, there was evidence following the flood that terrestrial-derived OM had increased in the estuary. First, low $\delta^{13} C_{\text {DIC }}$ values during September 2010 (between $-2 \%$ and $-18 \%$; Dias et al. 2014) indicate that the system was net heterotrophic. Second, the C: $\mathrm{N}_{\mathrm{POM}}$ ratio was $>10$ (TFW), suggesting a substantial contribution of terrestrial-derived OM to the POM pool (Hedges et al. 1986, 1997). The relatively high contribution of allochthonous OM to the food web during the low river discharge period may have been facilitated by both prolonged residence time and physical forces such as wind-driven or tidal mixing that can resuspend terrestrial-derived $\mathrm{OM}$ in the sediments, thereby increasing its availability to filter feeders (Goñi et al. 2009).

To the best of our knowledge, this is the first study that shows a time-lagged effect of a flood pulse to the estuarine food web. Although we did not measure the consequences of this flood to the structure and dynamics of the food web, we hypothesize that this scenario likely originates a mismatch between secondary and primary production, potentially reducing the phytoplankton-based estuarine production; contrarily, the organisms feeding on the detrital food web would be favored.

In contrast, the proportion of phytoplankton in the POM pool was higher in August 2011, especially in the TFW, (average values $>50 \%$, except in the marine stations), supporting more than $40 \%$ of the pelagic and benthic production.

In March 2011, during high river discharge, the average phytoplankton proportion in the POM pool was lower, up to $40 \%$, and the proportion of phytoplankton supporting pelagic and benthic production also decreased $(<40 \%)$. High river discharge can limit phytoplankton availability, production, and accumulation by increasing allochthonous $\mathrm{C}$ loadings, reducing light penetration, and decreasing residence time (Sin et al. 1999). During high discharge, the chl a concentration values were $\sim 1 \mu \mathrm{g} \mathrm{l}^{-1}$, one-third of the concentration determined in August 2011. Phytoplankton production may have been limited by low light penetration owing to a typical increase in turbidity during the winter, or phytoplankton was growing but rapidly exported from the estuary.

Contrary to our initial hypothesis, the contribution of allochthonous subsidies to the estuarine food web was lower during high river discharge. This may be related to the low residence times in this estuary during the winter $\left(<1.5 d_{i}\right.$ Ferreira et al. 2003), which may increase the outflow of particulates to the coastal marine environment. This scenario potentially decreases the connectivity between the freshwater and brackish estuarine food webs, because 
although materials circulate between habitats, their retention time is not long enough to be incorporated in the brackish food webs.

In contrast to 2009-2010, 2011 was an average hydrological year in the Minho River (Fig. 2; SNIRH 2012). During low river discharge, marine-derived OM inputs to the estuarine food web increased, increasing connectivity between the estuary and the marine ecosystem, and the exported freshwater POM was consumed in the brackish portion of the estuary, likely due to increased residence times.

\section{Food web modeling}

A critical assumption of the food web reconstruction based on stable isotope analysis is that the OM source values measured were similar over the isotopic turnover period of the organisms we sampled, about 2-3 mo. For individuals, the isotopic turnover period depends on both somatic growth and metabolic turnover rates; in organisms that grow rapidly, somatic growth rates essentially determine the isotopic turnover period (Martínez del Rio et al. 2009). Zooplankton turnover rates are generally $<1$ mo (Hoffman et al. 2007), thus reflecting temporal environmental variability. However, zooplankton collected in the brackish estuary might have been displaced downstream, especially during high discharge conditions. Our stable isotope data do not support this hypothesis, because calanoid copepods collected in the brackish portion of the estuary resembled the stable isotope ratios of brackish and marine taxa (e.g. polychaete larvae, Calanus spp.; March 2011) or were close to the stable isotope values of $C$. fluminea (September 2010, August 2011). Moreover, calanoid copepods collected in the brackish portion of the estuary were more ${ }^{13} \mathrm{C}$-enriched than those collected in the TFW.

The isotopic turnover rate of $C$. fluminea has not been determined, but the stable isotope values of other bivalves (Dreissena polymorpha, Corbula amurensis) are spatially and temporally well aligned with environmental processes (e.g. watershed inputs, river water chemistry) (Fry 2002, Fry \& Allen 2003). The same is likely true for $C$. fluminea owing to its rapid growth rate and similarly short life span (McMahon 2002, Thompson \& Parchaso 2010).

\section{Cross-habitat and cross-ecosystem connectivity}

Adjacent habitats and ecosystems can be linked both by energy exchange and organisms' move- ments, as it is the case of estuarine fish (Hoffman et al. 2015, Selleslagh et al. 2015). In this study, we examined primary consumers with no or with more limited abilities to translocate to different habitats to feed, so they had to utilize the OM sources available locally. However, multiple and distinct sources of OM supported primary consumers throughout the estuary. In the TFW, the contribution of terrestrialderived OM (POM, plant detritus) to primary consumers' biomass was the highest, while the contribution of marine OM (phytoplankton, POM, macroalgae) was limited to the estuary mouth.

Terrestrial inputs into aquatic ecosystems are often equal, or larger than the autochthonous primary production (Meili et al. 1996). Nonetheless, it is commonly assumed that estuarine secondary production is primarily supported by autochthonous production, especially phytoplankton (Deegan \& Garritt 1997, Chanton \& Lewis 2002) because this is considered a high quality food source. However, there is growing evidence that terrestrial inputs can subsidize estuarine food webs, supporting up to $80 \%$ of invertebrates and fish biomass (Kasai \& Nakata 2005, Hoffman et al. 2008, Cole \& Solomon 2012, this study). Although the mechanisms underlying the use of refractory material are poorly understood, terrestrial OM may become available to pelagic consumers through microbial uptake of terrestrial dissolved organic carbon followed by direct or indirect consumption of the microbes (Berggren et al. 2010), or direct consumption of terrestrial dissolved organic carbon (Speas \& Duffy 1998), or direct consumption of terrestrialderived particles (Cole et al. 2006). However, the consequences of the direct or indirect use of refractory material to the food web and to the secondary production are still poorly understood.

External subsidies to the estuarine food web were not limited to the land-water connection. As hypothesized, the tidal incursion provided marine POM to the estuarine food web during low discharge conditions. During August 2011, some consumers (e.g. Centropages, Oikopleura, and Ostracoda) presented high $\delta^{13} \mathrm{C}$ values in the brackish portion of the estuary, suggesting the consumption of a ${ }^{13} \mathrm{C}$-enriched mixture of OM sources, including macroalgae and marine POM. The importance of marine material (phytoplankton and POM) increased with the proximity to the estuary mouth, where it comprised 26-88\% of calanoid copepods' biomass.

In September 2010, OM exported from the TFW to the brackish portion of the estuary was consumed by primary producers and incorporated into the food web. Some brackish water consumers had low $\delta^{13} \mathrm{C}$ 
values (calanoid copepods, Caridea larvae, C. fluminea), suggesting the consumption of a ${ }^{13} \mathrm{C}$-depleted source, such as brackish phytoplankton, SOM or terrestrial-derived freshwater POM. Accordingly, the dual-stable isotope mixing model attributed between $20 \%$ (calanoid copepods) and $40 \%$ (C. fluminea) of terrestrial-derived freshwater POM to primary consumers' biomass in the brackish estuary.

In August 2011, calanoid copepods and C. fluminea from the brackish portion of the estuary relied on terrestrial plants or freshwater POM largely comprised of phytoplankton $(74.4 \pm 19.0 \%)$. Their high $\delta^{15} \mathrm{~N}$ values, however, indicate that the most likely source was freshwater POM. Thus, as in September 2010, POM was exported from the TFW portion of the estuary, subsidizing up to $80 \%$ of consumers biomass in the lower estuary.

In March 2011, the isotopic composition and $\mathrm{C}: \mathrm{N}_{\mathrm{POM}}$ ratio provided evidence that riparian or upland-derived OM (or both) was transported to the lower portion of the estuary, but the stable isotopic composition of zooplankton do not indicate that this material was consumed. Instead, zooplankton were consuming a ${ }^{13} \mathrm{C}$-enriched source (e.g. macroalgae, brackish phytoplankton), and ${ }^{15} \mathrm{~N}$-depleted sources (e.g. SOM). We estimated that SOM was the most important source contributing to calanoid copepod biomass $(27-61 \%)$, which can be accessed through sediment resuspension during high river discharge, or through vertical migrations in the water column. Because the $\delta^{13} \mathrm{C}$ and $\delta^{15} \mathrm{~N}$ values of calanoid copepods were similar to those from polychaete larvae and ostracods, they could also be using the same OM sources. Marine intrusion was confined to the first $6 \mathrm{~km}$ of the estuary, and thus, it is possible that during high discharge, the particulate marine subsidies to the estuary are minor. If consumers were using marine phytoplankton, which has a typical $\delta^{15} \mathrm{~N}$ of $6 \pm$ $1.5 \%$ (Bode et al. 2007) and $\delta^{13} \mathrm{C}$ of $-20.5 \pm 1.3 \%$ (McMahon et al. 2013), and assuming a trophic fractionation of $+3.4 \%$ for $\mathrm{N}$ and $+0.4 \%$ for $\mathrm{C}$, their $\delta^{13} \mathrm{C}$ and $\delta^{15} \mathrm{~N}$ values would have to be close to $-21 \%$ for $\delta^{13} \mathrm{C}$ and higher than $8 \%$ for $\delta^{15} \mathrm{~N}$, which was not the case.

\section{CONCLUSIONS}

In the Minho river estuary, primary consumers largely relied on autochthonous OM, but they apparently can adapt to low food quality conditions during and for a long time after high-flow pulses, by using relatively low quality $\mathrm{OM}$ sources (i.e. terrestrial- derived OM). The ability of primary consumers to utilize the external subsidies from terrestrial and marine ecosystems, and to consume both pelagic and benthic OM sources facilitates connectivity among ecosystems and habitats, linking terrestrial ecosystems and the sea with the estuarine pelagic and benthic environments. Nonetheless, further studies are needed to understand how the degree of connectivity between ecosystems and habitats can affect the carrying capacity of the ecosystem.

Acknowledgements. We thank Katie Bentley, Jacinto Cunha, Martina Ilarri and Luís Vieira for helping with POM and zooplankton samples; Rute Pinto for providing the map of the study area; and 3 anonymous reviewers for their helpful comments. E.D. (SFRH/BPD/104019/2014) and P.M. (SFRH/BPD/40832/2007， INCENTIVO/MAR/UI0350/2014) were supported by post-doc scholarships financed by the Foundation for Science and Technology (FCT). This work was partially supported by the Strategic Funding UID/ Multi/04423/2013 through national funds provided by FCT and European Regional Development Fund (ERDF), in the framework of the programme PT2020. The views expressed in this paper are those of the authors and do not necessarily reflect the views or policies of the US EPA.

\section{LITERATURE CITED}

Alves AM (1996) Causas e processos da dinâmica sedimentar na evolução actual do litoral do Alto Minho. PhD dissertation, Universidade do Minho

Anderson MJ, Gorley RN, Clarke KR (2008) PERMANOVA+ for PRIMER: guide to software and statistical methods. PRIMER-E, Plymouth

Antonio E, Kasai A, Ueno M, Won N, Ishihi Y, Yohoyama H, Yamashita Y (2010) Spatial variation in organic matter utilization by benthic communities from Yura River-Estuary to offshore of Tango Sea, Japan. Estuar Coast Shelf Sci 86:107-117

Atwood TB, Wiegner TN, MacKenzie RA (2012) Effects of hydrological forcing on the structure of a tropical estuarine food web. Oikos 121:277-289

Berggren M, Ström L, Laudon H, Karlsson J and others (2010) Lake secondary production fueled by rapid transfer of low molecular weight organic carbon from terrestrial sources to aquatic consumers. Ecol Lett 13:870-880

Bode A, Alavarez-Ossorio MT, Cunha ME, Garrido S and others (2007) Stable nitrogen isotope studies of the pelagic food web on the Atlantic shelf of the Iberian Peninsula. Prog Oceanogr 74:115-131

> Branco AB, Kremer JN (2005) The relative importance of chlorophyll and colored dissolved organic matter (CDOM) to the prediction of the diffuse attenuation coefficient in shallow estuaries. Estuaries 28:643-652

Canuel EA, Cloern JE, Ringelberg DB, Guckert JB (1995) Molecular and isotopic tracers used to examine sources of organic matter and its incorporation into the food webs of San Francisco Bay. Limnol Oceanogr 40:67-81

Chanton J, Lewis FG (2002) Examination of coupling between primary and secondary production in a river-dominated estuary: Apalachicola Bay, Florida, USA. Limnol 
Oceanogr 47:683-697

Clarke KR, Gorley RN (2006) PRIMER v6: user manual/tutorial. PRIMER-E, Plymouth

Clarke KR, Somerfield PJ, Gorley RN (2008) Testing of null hypotheses in exploratory community analyses: similarity profiles and biota-environment linkage. J Exp Mar Biol Ecol 366:56-69

> Cloern JE, Canuel EA, Harris D (2002) Stable carbon and nitrogen isotope composition of aquatic and terrestrial plants of the San Francisco Bay estuarine system. Limnol Oceanogr 47:713-729

Cole JJ, Solomon CT (2012) Terrestrial support of zebra mussels and the Hudson River food web: a multi-isotope, Bayesian analysis. Limnol Oceanogr 57:1802-1815

> Cole JJ, Carpenter SR, Pace ML, Van de Bogert MC, Kitchell JL, Hodgson JR (2006) Differential support of lake food webs by three types of terrestrial organic carbon. Ecol Lett 9:558-568

Cole JJ, Carpenter SR, Kitchell J, Pace ML, Solomon CT, Weidel B (2011) Strong evidence for terrestrial support of zooplankton in small lakes based on stable isotopes of carbon, nitrogen, and hydrogen. Proc Natl Acad Sci USA 108:1975-1980

de Kluijver A, Schoon PL, Downing JA, Schouten S, Middelburg JJ (2014) Stable carbon isotope biogeochemistry of lakes along a trophic gradient. Biogeosciences 11: 6265-6276

> Deegan LA, Garritt RH (1997) Evidence for spatial variability in estuarine food webs. Mar Ecol Prog Ser 147:31-47

> DeNiro MJ, Epstein S (1977) Mechanism of carbon isotope fractionation associated with lipid synthesis. Science 197: 261-263

> Dias E, Morais P, Antunes C, Hoffman JC (2014) Linking terrestrial and benthic estuarine ecosystems: organic matter sources supporting the high secondary production of a non-indigenous bivalve. Biol Invasions 16:2163-2179

Ferreira JG, Simas T, Nobre A, Silva MC, Schifferegger K, Lencart-Silva J (2003) Identification of sensitive areas and vulnerable zones in transitional and coastal Portuguese systems. Application of the United States National Estuarine Eutrophication Assessment to the Minho, Lima, Douro, Ria de Aveiro, Mondego, Tagus, Sado, Mira, Ria Formosa and Guadiana systems. INAG/ IMAR Tech Rep

> Feuchtmayr H, Grey J (2003) Effect of preparation and preservation procedures on carbon and nitrogen stable isotope determinations from zooplankton. Rapid Commun Mass Spectrom 17:2605-2610

France RL (1995) Carbon-13 enrichment in benthic compared to planktonic algae: foodweb implications. Mar Ecol Prog Ser 124:307-312

Fry B (2002) Conservative mixing of stable isotopes across estuarine salinity gradients: a conceptual framework for monitoring watershed influences on downstream fisheries production. Estuaries 25:264-271

- Fry B, Allen YC (2003) Stable isotopes in zebra mussels as bioindicators of river-watershed linkages. River Res Appl 19:683-696

Fry B, Sherr EB (1984) $\delta^{13} \mathrm{C}$ measurements as indicators of carbon flow in marine and freshwater ecosystems. Contr Mar Sci 27:15-47

Goñi MA, Voulgaris G, Kim YH (2009) Composition and fluxes of particulate organic matter in a temperate estuary (Winyah Bay, South Carolina, USA) under contrasting physical forcings. Estuar Coast Shelf Sci 85:273-291
Hedges JI, Clark WA, Quay PD, Richey JE, Devol AH, Santos UM (1986) Compositions and fluxes of particulate organic material in the Amazon River. Limnol Oceanogr 31:717-738

- Hedges JI, Keil RG, Benner R (1997) What happens to terrestrial organic matter in the ocean? Org Geochem 27: $195-212$

Hoffman JC, Bronk DA (2006) Interannual variation in stable carbon and nitrogen isotope biogeochemistry of the Mattaponi River, Virginia. Limnol Oceanogr 51:2319-2332

Hoffman JC, Bronk DA, Olney JE (2007) Tracking nursery habitat use by young American shad in the York River estuary, Virginia using stable isotopes. Trans Am Fish Soc 136:1285-1297

- Hoffman JC, Bronk DA, Olney JE (2008) Organic matter sources supporting lower food web production in the tidal freshwater portion of the York River estuary, Virginia. Estuaries Coasts 31:898-911

Hoffman JC, Kelly JR, Peterson GS, Cotter AM (2015) Landscape-Scale food webs of fish nursery habitat along a river-coast mixing zone. Estuaries Coasts 38:1335-1349

> Kasai A, Nakata A (2005) Utilization of terrestrial organic matter by the bivalve Corbicula japonica estimated from stable isotope analysis. Fish Sci 71:151-158

Kendall C, Silva SR, Kelly VJ (2001) Carbon and nitrogen isotopic compositions of particulate organic matter in four large river systems across the United States. Hydrol Processes 15:1301-1346

Kohler AE, Pearsons TN, Zendt JS, Mesa MG, Johnson CL, Connolly PJ (2012) Nutrient enrichment with salmon carcass analogs in the Columbia River Basin, USA: A stream food web analysis. Trans Am Fish Soc 141:802-824

> Logan JM, Jardine TD, Miller TJ, Bunn SE, Cunjak RA, Lutcavage ME (2008) Lipid corrections in carbon and nitrogen stable isotope analyses: comparison of chemical extraction and modelling methods. J Anim Ecol 77:838-846

> Lorenzen CJ (1967) Determination of chlorophyll and pheo-pigments: Spectrophotometric equations. Limnol Oceanogr 12:343-346

> Lorrain A, Savoye N, Chauvaud L, Paulet YM, Naulet N (2003) Decarbonation and preservation method for the analysis of organic $\mathrm{C}$ and $\mathrm{N}$ contents and stable isotope ratios of low-carbonated suspended particulate material. Anal Chim Acta 491:125-133

> Martínez del Rio C, Wolf N, Carleton SA, Gannes LZ (2009) Isotopic ecology ten years after a call for more laboratory experiments. Biol Rev Camb Philos Soc 84:91-111

> Marty J, Planas D (2008) Comparison of methods to determine algal $\delta^{13} \mathrm{C}$ in freshwater. Limnol Oceanogr Methods 6:51-63

> McMahon RF (2002) Evolutionary and physiological adaptations of aquatic invasive animals: $r$ selection versus resistance. Can J Fish Aquat Sci 59:1235-1244

McMahon K, Hamady LL, Thorrold SR (2013) A review of ecogeochemistry approaches to estimating movements of marine animals. Limnol Oceanogr 58:697-714

Meili M, Kling GW, Fry B, Bell RT, Ahlgren I (1996) Sources and partitioning of organic matter in a pelagic microbial food web inferred from the isotopic composition $\delta^{13} \mathrm{C}$ and $\delta^{15} \mathrm{~N}$ of zooplankton species. Arch Hydrobiol Spec Issue Adv Limnol 48:53-61

Mook WG, Tan FC (1991) Stable carbon isotopes in rivers and estuaries: In: Degens ET, Kemp S, Richey JE (eds) Biogeochemistry of major world rivers. John Wiley, Chichester, p 245-264 
Naiman RJ, Bilby RE, Schindler DE, Helfield JM (2002) Pacific salmon, nutrients, and the dynamics of freshwater and riparian ecosystems. Ecosystems 5:399-417

Nixon S, Buckley BA (2002) 'A strikingly rich zone'-Nutrient enrichment and secondary production in coastal marine ecosystems. Estuaries 25:782-796

Parnell AC, Inger R, Bearhop S, Jackson AL (2010) Source partitioning using stable isotopes: coping with too much variation. PLoS ONE 5:e9672

Peterson BJ, Fry B (1987) Stable isotopes in ecosystem studies. Annu Rev Ecol Syst 18:293-320

Post DM (2002) Using stable isotopes to estimate trophic position: models, methods, and assumptions. Ecology 83: 703-718

Reis JL, Martinho AS, Pires-Silva AA, Silva AJ (2009) Assessing the influence of the river discharge on the Minho Estuary tidal regime. J Coastal Res Spec Issue 56: 1405-1409

Riley RH, Townsend CR, Raffaelli DA, Flecker AS (2004) Sources and effects of subsidies along the stream-estuary continuum. In: Polis GA, Power ME, Huxel GR (eds) Food webs at the landscape level. The University of Chicago Press, Chicago, IL, p 241-260

Selleslagh J, Blanchet H, Bachelet G, Lobry J (2015) Feeding habitats, connectivity and origin of organic matter supporting fish populations in an estuary with a reduced intertidal area assessed by stable isotope analysis. Estuaries Coasts 38:1431-1447

Editorial responsibility: Antonio Bode, A Coruña, Spain
Sheaves M (2009) Consequences of ecological connectivity: the coastal ecosystem mosaic. Mar Ecol Prog Ser 391: $107-115$

Sin Y, Wetzel RL, Anderson IC (1999) Spatial and temporal characteristics of nutrient and phytoplankton dynamics in the York River estuary, Virginia: analyses of long-term data. Estuaries 22:260-275

Smith BN, Epstein S (1971) Two categories of ${ }^{13} \mathrm{C} /{ }^{12} \mathrm{C}$ ratios for higher plants. Plant Physiol 47:380-384

Smyntek PM, Teece MA, Schulz KL, Thackeray SJ (2007) A standard protocol for stable isotope analysis of zooplankton in aquatic food web research using mass balance correction models. Limnol Oceanogr 52:2135-2146

SNIRH (2012) Sistema nacional de informação de recursos hídricos. Available at http://snirh.pt (accessed 31 Oct 2012)

Speas DW, Duffy WC (1998) Uptake of dissolved carbon (DOC) by Daphnia pulex. J Freshw Ecol 13:457-463

Thompson JK, Parchaso F (2010) Corbula amurensis conceptual model. US Geological Survey, Washington, DC

Valiela I, Bartholomew M (2015) Land-Sea coupling and global-driven forcing: following some of Scott Nixon's challenges. Estuaries Coasts 38:1189-1201

Vanni MJ, DeAngelis DL, Schindler DE, Huxel GR (2004) Overview: cross-habitat flux of nutrients and detritus. In: Polis GA, Power ME, Huxel GR (eds) Food webs at the landscape level. The University of Chicago Press, Chicago, IL, p 3-11

Submitted: September 24, 2015; Accepted: June 7, 2016 Proofs received from author(s): July 15, 2016 